\title{
Autonomous functioning thyroid nodule a rare paediatric diagnosis
}

\author{
Vicente Rey y Formoso ${ }^{1}$, Daniela Salazar ${ }^{2}$, Sara Fernandes ${ }^{3}$, Sofia Ferreira ${ }^{3}$, Norberto Estevinho ${ }^{3}$, \\ Cíntia Castro Correia ${ }^{3}$
}

${ }^{1}$ Paediatrics Department, Maternal and Paediatrics Centre, São João University and Hospital Centre, Porto, Portugal ${ }^{2}$ Department of Endocrinology, Diabetes, and Metabolism, São João University and Hospital Centre, Porto, Portugal

${ }^{3}$ Pediatric Surgery Department, Maternal and Paediatrics Centre, São João University and Hospital Centre, Porto, Portugal ${ }^{4}$ Pediatric Endocrinology Unit, Paediatrics Department, Maternal and Paediatrics Centre, São João University and Hospital Centre, Porto, Portugal

Key words: thyroid nodule; pediatrics; autonomous functioning thyroid nodules; toxic adenoma; thyroid scintigraphy

Autonomous functioning thyroid nodules (AFTN) may be defined as nodules in which follicular cells have a TSH (and antibody)-independent function [1-3]. These are not uncommon in adults but are exceptionally rare in patients under 18 years of age [3], with a higher prevalence in females [1,2].

Patients with AFTN may either exhibit symptoms of hyperthyroidism or be clinically euthyroid [1, 3-5]. Symptomatic hyperthyroidism and/or the detection of a cervical mass are, most often, the presenting features [3].

Autonomous functioning thyroid nodules are diagnosed by a suppressed TSH and increased, nodule-specific uptake on thyroid scintigraphy $[2,3,5]$, and surgical resection is, according to current guidelines, the recommended approach for most AFTN in this age group [3,5]. A 17-year-old female, obese (BMI $36.7 \mathrm{~kg} / \mathrm{m}^{2}, \mathrm{P}>97$ ), with no other relevant priors, sought medical advice in our Emergency Department (ED), for a progressively growing cervical mass, noticed in the last month, that caused intermittent dysphagia. At physical examination, an anterior mass was visible and palpable, $4 \mathrm{~cm}$ in its largest diameter, soft, elastic, and painless to palpation (Fig. 1). An ED ultrasound described a mixed nature thyroid nodule in the transition of the left lobule to the isthmus, measuring $3.7 \times 1.5 \mathrm{~cm}$. No irregular margins or calcifications were described and no other surrounding masses or adenomegalies were found. The patient was discharged after Paediatric Oncology and Endocrinology consultations were scheduled.

Ten days later, on her first outpatient evaluation, thyroid function was accessed, revealing normal fT4 and TSH levels $(10.43 \mathrm{pmol} / \mathrm{L}$ and $0.52 \mathrm{mIU} / \mathrm{mL}$, re-

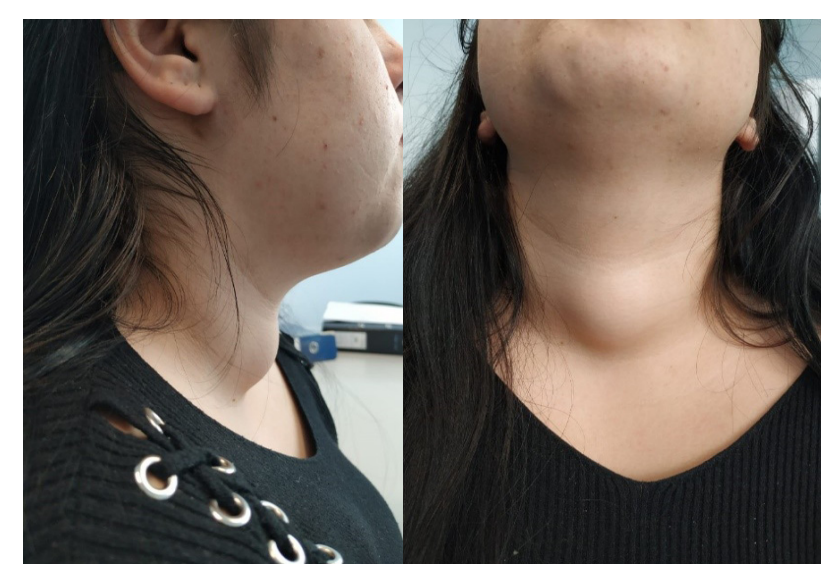

Figure 1. Macroscopic aspect of the mass on presentation

spectively) and negative thyroid antibodies (TPOAb, $\mathrm{TRAb}$, and $\operatorname{TgAb}$ ), and a fine needle aspiration biopsy was performed, identifying the lesion as a benign follicular nodule. After discussion in a Paediatric Oncology Group Consultation (POGC), an expectant management strategy was adopted.

Four months later, the patient maintained intermittent dysphagia but also described occasional breathing discomfort and feeling "constantly tired". A new ultrasound (Fig. 2) described an enlargement of the lesion $(4 \times 3.8 \times 2.2 \mathrm{~cm})$ which retained its radiological characteristics. On a new POGC, surgical excision of the mass was decided and scheduled, based on the patient's symptoms and the nodule's apparent continuous growth.

Thyroid function was, at the time, reassessed, revealing normal fT4 levels but clearly suppressed 


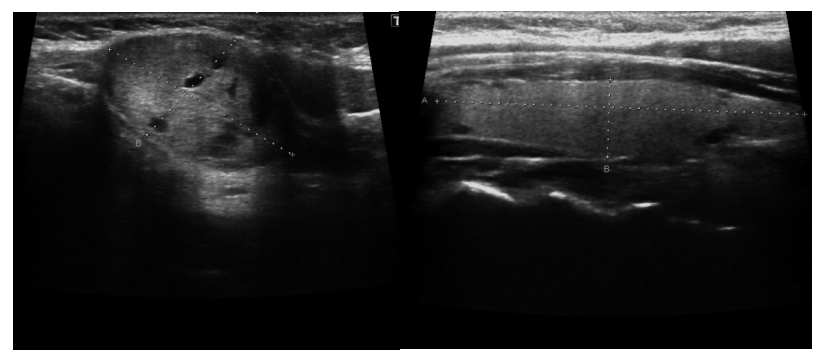

Figure 2. Ultrasound image of the lesion
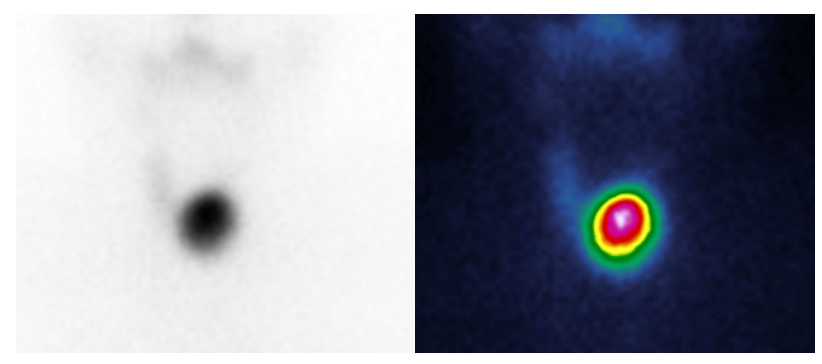

Figure 3. $I^{131}$ Scintigraphy image. A specific hypercaptation region can be noticed while minimal radionuclide uptake is present in the extranodular area

TSH and elevated thyroglobulin levels (respectively, $12.10 \mathrm{pmol} / \mathrm{L}, 0.09 \mathrm{mIU} / \mathrm{mL}$ and $386 \mu \mathrm{g} / \mathrm{L}$ ). At this point suspicions arose of a possible AFTN, and a subsequent thyroid scintigraphy further confirmed that hypothesis, describing a distinctly increased uptake of $\mathrm{I}^{131}$ by the mass and decreased uptake by the remaining thyroid tissue (Fig. 3). The patient was started on Atenolol and Metibasol with subsequent improvement of thyroid function levels (fT4 $10.04 \mathrm{pmol} / \mathrm{L}$ and $11.07 \mathrm{pmol} / \mathrm{L}$; TSH $0.68 \mathrm{mIU} / \mathrm{mL}$ and $0.93 \mathrm{mIU} / \mathrm{mL}$, at 1 and 4 months of treatment, respectively).

A few months later, the patient underwent a left hemithyroidectomy and isthmectomy without any intercurrences (Fig. 4). Surgical pathology of the lesion described an encapsulated nodule compatible with a follicular adenoma, morphologically consistent with previous suspicions of an AFTN.

After the surgery, all pharmacological treatment was suspended, and the patient currently remains euthyroid and completely asymptomatic (Fig. 5).

We describe the case of a paediatric patient who sought medical attention after noticing a growing anterior cervical mass. Although initial thyroid function studies did not show any imbalances, a clearly suppressed TSH level, which suggested TSH-independent thyroid hormone production, was documented on follow-up. This led to the suspicion of an AFTN, which was subsequently confirmed in an unambiguous $\mathrm{I}^{131}$ scintigraphy.

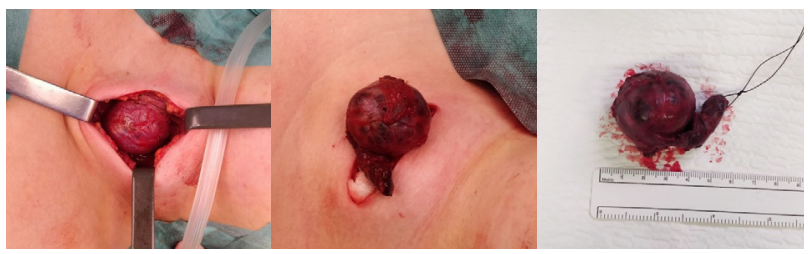

Figure 4. Photographs of the nodule in situ and after surgical resection

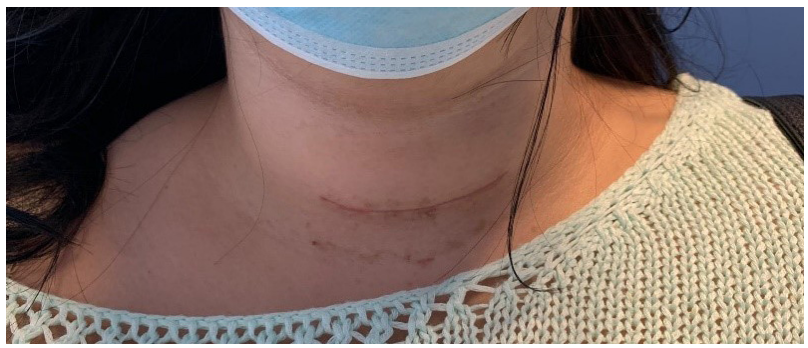

Figure 5. The patient's anterior cervical area, 40 days after surgery

The lesion's size and apparent continuous growth led to a surgical approach, which, as previously mentioned, is the recommended approach for most paediatric AFTN.

Although rare, AFTN should be part of the differential diagnosis for thyroid nodules in the paediatric population, even if the patient is clinically euthyroid and initial thyroid function assessments are normal. Thyroid function should be routinely assessed in patients with thyroid nodules, and, if suppressed TSH levels are found, a thyroid scintigraphy should be performed.

\section{Conflicts of interest and funding}

The authors declare there are no conflicts of interest.

\section{Funding}

The authors received no specific funding for this work.

\section{References}

1. Niedziela M, Breborowicz D, Trejster E, et al. Hot nodules in children and adolescents in western Poland from 1996 to 2000: clinical analysis of 31 patients. J Pediatr Endocrinol Metab. 2002; 15(6): 823-830, doi: 10.1515/jpem.2002.15.6.823, indexed in Pubmed: 12099393.

2. Ly S, Frates MC, Benson CB, et al. Features and Outcome of Autonomous Thyroid Nodules in Children: 31 Consecutive Patients Seen at a Single Center. J Clin Endocrinol Metab. 2016; 101(10): 3856-3862, doi: 10.1210/jc.2016-1779, indexed in Pubmed: 27501280.

3. Grob F, Deladoëy J, Legault L, et al. Autonomous adenomas caused by somatic mutations of the thyroid-stimulating hormone receptor in children. Horm Res Paediatr. 2014; 81(2): 73-79, doi: 10.1159/000357143, indexed in Pubmed: 24480816.

4. Guille JT, Opoku-Boateng A, Thibeault SL, et al. Evaluation and management of the pediatric thyroid nodule. Oncologist. 2015; 20(1): 19-27, doi: 10.1634/theoncologist.2014-0115, indexed in Pubmed: 25480825.

5. Francis GL, Waguespack SG, Bauer AJ, et al. American Thyroid Association Guidelines Task Force. Management Guidelines for Children with Thyroid Nodules and Differentiated Thyroid Cancer. Thyroid. 2015; 25(7): 716-759, doi: 10.1089/thy.2014.0460, indexed in Pubmed: 25900731. 